XIV Российская национальная конференция по сейсмостойкому строительству и сейсмическому районированию (с международным участием). Сборник материалов

УДК 624.046.2

DOI 10.37153/2687-0045-2021-14-129-132

\title{
О НЕОБХОДИМОСТИ НОРМИРОВАНИЯ ОСОБОГО ПРЕДЕЛЬНОГО СОСТОЯНИЯ
}

\section{ON THE NECESSITY OF REGULATION OF A SPECIAL LIMIT STATE}

Трекин Николай Николаевич, доктор технических наук, профессор, начальник отдела конструктивных систем №1 АО «ЦНИИПромзданий»; 127238 Россия, Москва, Дмитровское шоссе, д.46, корп. 2; e-mail: nik-trekin@yandex.ru, +7 (903) 794-64-38.

Кодыш Эмиль Наумович, доктор технических наук, профессор, главный научный сотрудник АО «ЦНИИПромзданий»; 127238 Россия, Москва, Дмитровское шоссе, д.46, корп. 2; e-mail: otks@yandex.ru, +7 (903) 794-64-37.

Терехов Иван Александрович, кандидат технических наук, заведующий сектором отдела конструктивных систем №1 АО «ЦНИИПромзданий»; 127238 Россия, Москва, Дмитровское шоссе, д.46, корп. 2; e-mail: otks@yandex.ru, +7 (985) 141-01-90.

Trekin N. Nikolaevich, Doctor of Technical Sciences, Professor, head of the Department of structural systems №1 of JSC "Tsniipromzdaniy"; 46, bldg. 2, Dmitrovskoe Shosse, Moscow, 127238, Russia, e-mail: nik-trekin@yandex.ru, +7 (903) 794-64-38.

Emil N. Kodysh, Doctor of Technical Sciences, Professor, Chief Researcher of JSC "Tsniipromzdaniy"; 46, bldg. 2, Dmitrovskoe Shosse, Moscow, 127238, Russia, e-mail: otks@yandex.ru, +7 (903) 794-64-37.

Ivan A. Terekhov, Candidate of Technical Sciences, head of the structural systems sector №1 of JSC "Tsniipromzdaniy"; 46, bldg. 2, Dmitrovskoe Shosse, Moscow, 127238, Russia, e-mail: otks@narod.ru, +7 (985) 141-01-90.

Аннотация: В настоящее время в проектной практике все чаще приходится сталкиваться с учетом аварийных расчетных ситуаций, приводящих к развитию в конструкциях больших пластических деформаций. Такое состояние конструкций выходит за рамки действующих требований метода предельных состояний. Для зданий повышенного уровня ответственности учет аварийных расчетных ситуаций производится в обязательном порядке в виде рассмотрения различных сценариев отказа несущих элементов и анализа сопротивления несущей системы прогрессирующему обрушению. Одним из способов повышения расчетной устойчивости зданий при отказе несущей конструкции является более полный учет напряженно-деформированного состояния элементов и их сопряжений в стадиях близкой к пределу несущей способности и при разгрузке. Расчетный анализ показал, что для этого применим известный метод предельного равновесия. На примере многоэтажного каркаса производственного здания из сборного железобетона показана эффективность применяемой методики.

Ключевые слова: несущая способность, особое предельное состояние, шарнир пластичности, экстремальные расчетные ситуации, предельные деформации арматуры и бетона

Abstract: At present, in design practice, it is increasingly necessary to deal with the calculation of emergency situations leading to the development of large plastic deformations in structures. 
XIV Российская национальная конференция по сейсмостойкому строительству и сейсмическому районированию (с международным участием). Сборник материалов

This state of structures is beyond the scope of the current requirements of the limit state method. For buildings with a higher level of responsibility, the calculation of emergency design situations is mandatory in the form of considering various scenarios of failure of load-bearing elements and analysis of the resistance of the load-bearing system to progressive collapse. One of the ways to increase the design stability of buildings in the event of a failure of the supporting structure is a more complete account of the stress-strain state of elements and their interfaces in stages close to the bearing capacity limit and during unloading. The computational analysis showed that the well-known method of limiting equilibrium is applicable for this. On the example of a multistorey frame of an industrial building made of prefabricated reinforced concrete, the effectiveness of the applied method is shown.

Keywords: load-bearing capacity, special limit state, plastic hinge, extreme design situations, ultimate deformations of reinforcement and concrete

Современные методы расчета строительных конструкций основываются на методе предельных состояний. Для расчета на проектные эксплуатационные нагрузки установлены две группы предельных состояний, критерии которых обеспечивают нормальные условия эксплуатации и необходимую надежность строительных конструкций. В последнее время все чаще проектная практика сталкивается с необходимостью учета экстремальных ситуаций, условия которых выводят конструкцию за рамки критериев двух групп предельных состояний. Это аварийные ситуации при взрывах, провалах грунта и т.п. Учет стадии работы конструкций за пределами действующих критериев предельных состояний уже много лет используется в расчетах на сейсмическое воздействие в виде поправочных коэффициентов.

Исследования последних лет показали, что снижение материальных затрат при обеспечении защиты от прогрессирующего обрушения или повышение живучести несущей строительной системы может быть осуществлено только с учетом допущения больших пластических деформаций, включая стадию, предшествующую разрушению [3]. Это подтверждается известным методом предельного равновесия [1], при использовании которого величина несущей способности конструкции выше результатов, полученных при расчете по нормируемым двум группам предельных состояний с учетом допустимых неупругих деформаций.

Следует отметить, что характеристики пластического шарнира уже превышают требования обеспечения нормальной эксплуатации конструкции из-за развития больших пластических деформаций в арматуре и бетоне, а следовательно, прогибов. Этот факт уже требует нормирования области применения $[2,4,5]$.

В связи с этим возникает необходимость введения в практику расчетов конструкций при аварийных расчетных ситуациях особого предельного состояния состояния конструкции после превышения границы несущей способности по первому предельному состоянию, в котором она не полностью соответствуют функциональным требованиям, дальнейшее увеличение нагрузок и/или воздействий приводит к ее разрушению.

Особую актуальность и эффективность введение особого предельного состояния имеет при расчетном анализе сопротивления несущей строительной системы прогрессирующему обрушению. Наглядно это можно продемонстрировать на примере каркасных систем, где достаточно очевидны расчетные схемы и варианты образования механизмов разрушения.

При удалении одного несущего элемента каркаса здания в соответствии с требованиями по проектированию защиты от прогрессирующего обрушения достаточно рассмотреть плоскую стержневую систему, «n» раз статически неопределимую. Полное 
XIV Российская национальная конференция по сейсмостойкому строительству и сейсмическому районированию (с международным участием). Сборник материалов

разрушение каркаса или его части произойдет после превращения несущей системы в механизм. Это можно смоделировать путем образования пластических шарниров, которые превращают пространственную или плоскую раму в кинематически изменяемую систему. Их количество должно превышать как минимум на единицу степень статической неопределимости. Максимальное количество пластических шарниров следует определять методом последовательных приближений, вставляя пластические шарниры последовательно в наиболее напряженные сечения после изменения расчетной схемы. Если в системе достигнуто равновесие до образования $\mathrm{n}+1$ шарниров, то конструкция не разрушится. Подобный анализ был на практике произведен с рамным каркасом многоэтажного производственного здания из сборного железобетона. Проверка напряженно-деформированного состояния плоской рамы при последовательном удалении средней и крайней колонны с учетом рекомендаций по характеристикам материалов и нагрузочным факторам СП 385.1325800.2018 позволил выявить резервы и показал их достаточную несущую способность при минимальных дополнительных конструктивных мероприятиях.

Анализ проведенных экспериментальных работ с изгибаемыми балками и теоретических исследований подтвердил, что оптимально запроектированные по действующим нормам балки имеют резерв по прочности до $25 \%$, а по деформативности до $35 \%$.

Таким образом, учет особого предельного состояния дает ощутимый эффект, однако для установления критериев работы различных конструкций в стадии, близкой к разрушению, и на этапе снижения сопротивления, в том числе и при сейсмических воздействиях, необходимо провести дополнительные исследования.

\section{Список литературы}

1. Гвоздев А.А. Расчет несущей способности конструкций по методу предельного равновесия. - М.: Госстройиздат, 1949. - 280 с.

2. Келасьев Н.Г., Трекин Н.Н., Кодыш Э.Н., Леонтьев Е.В., Терехов И.А., Шмаков С.Д. Конструктивные решения защиты одноэтажных каркасных зданий от прогрессирующего обрушения // Промышленное и гражданское строительство. - 2021. № 3. - С. 17-22.

3. Попов Н.Н., Плотников А.И., Белобров И.К. Работа изгибаемых элементов при снижении несущей способности // Бетон и железобетон. - 1986. - № 6. - С.19-20.

4. Трекин Н.Н., Кодыш Э.Н., Келасьев Н.Г. Использование резервов несущей способности железобетонных конструкций при кратковременном силовом воздействии // XIII Рос. нац. конф. по сейсмостойкому строительству и сейсмическому районированию (XIII РНКСС). - СПб, 2019. - С. 101-102.

5. Трекин Н.Н., Кодыш Э.Н. Особое предельное состояние железобетонных конструкций и его нормирование // Промышленное и гражданское строительство. - 2020. - № 5. - C. 4-9.

\section{References}

1. Gvozdev A.A. Raschet nesuschey sposobnosti konstrukciy po metodu predel'nogo ravnovesiya [Calculation of the load-bearing capacity of structures using the limit equilibrium method]. - Moscow, Gosstroyizdat Publ., 1949. 280 p. (In Russian).

2. Kelasyev N.G., Trekin N.N., Kodysh E.N., Leont'yev E.V., Terekhov I.A., Shmakov S.D. Structural Solutions for Protecting One-Story Frame Buildings from Progressive Collapse. Promyshlennoe i grazhdanskoe stroitel'stvo [Industrial and Civil Engineering], 2021, no. 3, pp. 17-22. (In Russian). 
XIV Российская национальная конференция по сейсмостойкому строительству и сейсмическому районированию (с международным участием). Сборник материалов

3. Popov N.N., Plotnikov A.I., Belobrov I.K. Operation of bending elements with reduced load capacity. Beton i zhelezobeton, 1986, no. 6, pp. 19-20. (In Russian).

4. Trekin N.N., Kodysh E.N., Kelasev N.G. Using reserves of load-bearing capacity of reinforced concrete structures under short-term force influence. XIII Rossiyskaya Nacional'naya Konferenciya po seysmostoykomu stroitel'stvu i seysmicheskomu rayonirovaniyu (XIII RNKSS) [XIII Russian national conference on earthquake-resistant construction and seismic zoning]. Saint-Petersburg, 2019, pp. 101-102. (In Russian).

5. Trekin N.N., Kodysh E.N. Special Limit Condition of Reinforced Concrete Structures and Its Normalization. Promyshlennoe i grazhdanskoe stroitel'stvo [Industrial and Civil Engineering], 2020, no. 5, pp. 4-9. (In Russian). 